\title{
A QUESTÃO DA MESTIÇAGEM NA AMÉRICA HISPÂNICA*
}

\section{Luciana Carneiro Hernandes CEFET-PR UNED -CP}

\begin{abstract}
* Artigo escrito com a colaboração da Professora Denise Vieira de Campos e publicado nos Anais do IV Congresso de Professores de Espanhol realizado em Curitiba - PR, no ano de 1991. As autoras eram, então, acadêmicas da Universidade Estadual Paulista - Campus de Assis.
\end{abstract}

Este trabalho visa tecer algumas considerações sobre a mestiçagem como elemento constituinte fundamental da identidade cultural da América Hispânica.

Mas...quem é, essencialmente o ser hispano-americano? A tendência atual é a descoberta do ser mestiço. Com muita honra! Ainda que não haja sinonímia perfeita, a mestiçagem - palavra forte de significação também forte - designa não apenas uma mescla racial-cultural, mas é o próprio gênesis ou alquimia fundamental da criação, caldo cultural a partir do qual brotam as características e especificidades de cada povo, verdades manifestas através das artes em geral e da literatura em particular. Questões de ordem histórica, no entanto, nos levam a observar a mestiçagem sempre sob um prisma pejorativo.

Em essência, o homem hispano-americano é a mescla de três grandes troncos étnico-culturais, bastante diversos no que tange a costumes, mas igualmente ricos em história e tradições. E é exatamente o choque provocado pelo encontro de culturas (1)diametralmente opostas, o responsável pelo nascimento desse homem "con los pies en el rosario, la cabeza blanca y el cuerpo pinto de indio o criollo", como afirma José Martí em seu ensaio "Nuestra América" (2). Esse homem hispano-americano, que ainda não descobriu ou construiu sua real identidade, nem se apercebeu de seu potencial criador, forma-se assim pela fusão de três culturas distintas, que não são mutuamente excludentes, mas sim estranhamente complementares.

Essa nova mentalidade se estrutura a partir da contraposição de antagonismos existentes e obtém o equilíbrio através da máxima tensão entre os três pontos. Porém, como afirmado anteriormente, devido a questões históricas - e que fique entendido aqui: devido à visão implícita do dominador expressa na elaboração dos documentos e relatos históricos - a mestiçagem, observada na maior parte das vezes apenas sob o prisma da mescla sangüínea, é uma questão tabu, identificada pelos povos como signo maior de impureza, quase uma aberração se comparada ao purismo racial. Note-se que um dos maiores insanos de nossa história, no auge de seus delírios, desejava a criação de uma raça ariana que, por ser pura, seria superior a qualquer outra.

Esquece-se, no entanto, o grande estrategista, que "si algun pueblo hubiera podido permanecer indefinidamente aislado y encerrado en su tierra original, hubiera quedado en un suerte de prehistoria congelada", afirmação esta contida no ensaio "El Mestizaje y el Nuevo Mundo" de Arturo Uslar-Pietri (3).

Deveríamos nos desprender de conceitos pré-concebidos, tão arraigados em nossa cultura, no que diz respeito à questão da mestiçagem para, assumindo o ser mestiço, podermos associar mestiçagem não mais à mistura de sobras, e sim à assimilação de virtudes diversas. A mestiçagem talvez seja o principal elemento de nossas angústias e contradições, pois tem o poder de inferir diretamente e quase simultaneamente tanto em nossa racionalidade como em nossa emocionalidade, sendo um dos elementos mais fortes na construção de nossa imagem ou visão de mundo, imagem esta que faz com que as culturas, qual Fênix, possam ressurgir das cinzas. José Lezama Lima, em "Imagen de América Latina" (4), tecendo considerações sobre o termo imagem e sua profunda significação, nos alerta que "la imagen producida por ese espacio que conoce, que crea una gnosis, nos cubre como una placenta (...) que nos protege $(. .$.$) de la mortal oscuridad que nos podía destruir antes de tiempo".$

Somente permitindo a dissolução de antigos preconceitos poderemos perceber a força dessa imagem, "tan ansiosa de conocimiento como de ser conocida" (5), e dar vazão ao latente potencial criador inerente ao ser mestiço, conhecendo a realidade-maravilhosa da América Hispânica sem as lentes distorcidas que o dominador implantou, aceitando, sem receios, a condição de sujeito-agente de um processo, abdicando o papel de vítimas (6) e construindo nossa história e nossa tão desejada identidade. 
A busca da identidade e de sua própria história, que empreende o homem americano, no entanto, se dá de maneira ambígua. Octavio Paz, no ensaio "Os filhos da Malinche" alerta para o fato de que o mexicano - e acredito que podemos estender esse conceito a outros povos hispano-americanos - na busca de sua identidade, luta contra fantasmas, que em muitos casos são vestígios de realidade passadas e que contam com um aliado secreto e poderoso a luta contra a vontade de ser: o medo de ser. A tensão entre um passado estranho - que não podemos abandonar e muito menos regressar - e um presente não menos estranho, exigem que vejamos a América Hispânica como uma verdade a ser inventada todos os dias. "No hay una sustancia original ni un pasado por rescatar: hay el vacío, la orfandad, la tierra del princípio no bautizada, la conversación entre los espejos" (7). O homem americano não quer ou não se atreve a ser ele mesmo porque, padecendo sua história ao invés de vivê-la, sente-se culpado "de um delito sem nome: o de ter nascido"(8). A relação desse homem americano com o mundo a seu redor se define, então, como busca, vontade de transcender o estado de exílio. Se define como "viva consciência da solidão, histórica e pessoal" (9).

Examinemos rapidamente o início do dilema da identidade. Cristovão Colombo, a primeira ponte cultural entre a América e a Europa, registra suas impressões do Novo Mundo recém-descoberto (porém já existente) sob o signo do fantástico-maravilhoso. Olhando sem ver, acaba por criar uma realidade particularizada, construída a partir de concepções de mundo pré-moldadas, as quais não permitem uma reflexão objetiva sobre a nova realidade. Observando este 'paraíso tropical' sob as lentes do fantástico-maravilhoso, Colombo esperava encontrar o El Dorado, uma montanha de prata em Potosí ou um jardim de ouro em Cuzco...

A visão deturpada, ou melhor dizendo, a visão subjetiva que Colombo, Cortez e outros estrangeiros dominadores tiveram da realidade com que se depararam, justapõe-se à visão não menos subjetiva dos nativos dominados que se maravilhavam quando, vendo homem e cavalo, pensavam estar diante de um deus centáurico que tinha o poder de dividir-se em duas partes distintas e ainda assim manter-se vivo. A imensa barreira que então se forma entre as diferentes visões de uma mesma realidade torna ainda mais difícil o êxito na busca da origem, a partir da qual o homem americano constrói sua realidade.

Mesmo com o claro propósito de manter-se em uma posição de dominador-descobridor, em que a 'pureza' de sua raça seria mantida, ainda que em contato com nativos 'ateus'e 'incultos', os representantes da dominação européia na América não conseguiram impedir a mescla de culturas, que foi inevitável...felizmente. Arturo Uslar-Pietri, en "El Mestizaje y el Nuevo Mundo" declara que "lo que vino a realizarse en América no fue la permanencia del mundo indígena, ni la prolongación de Europa. Lo que ocurrió fue otra cosa y por eso fue Nuevo Mundo desde el comienzo. El mestizaje comenzó por la lengua, por la cocina, por las costumbres"(10) .

A alquimia fundamental da criação na América Hispânica, como afirmado anteriormente, baseia-se no encontro de três grandes troncos étnico-culturais. A mescla ocorrida entre os compentes indígena e branco é, sem dúvida alguma, a mais estudada; talvez pelo grande conhecimento técnico e magnitude ritualesca apresentados pelo tronco indígena, que fascinou aos dominadores do mesmo modo que eles o fascinaram. Menos estudado, mas não menos importante, o negro é o outro elemento formador de nosso caldo cultural. Presença marcante de um mundo não latino, instrumentalizado pelo europeu que o trouxe da África desejando destituí-lo de qualquer traço de tradição ou história, "Ios esclavos retribuyeron a sus manos transmitiéndoles todo lo que pudieron conservar de su cultura, enseñandoles muchas cosas: desde cantar y bailar hasta luchar por su libertad"(11), nos diz César Fernández Moreno, na "Introdução" de "América Latina en su Cultura".

Seria interessante encerrar este trabalho ressaltando que a América Hispânica é, atualmente, a maior zona de mestiçagem do mundo...deveria, portanto, valorizar suas potencialidades, revigorando sua literatura, que é a síntese da América Mestiça. A mestiçagem pujante na América Hispânica vem confirmar o caráter universal do Novo Mundo antecipando a realidade futura, onde acima de raças e culturas, o homem será um...

NOTAS DE REFERÊNCIA

1- "...sería cerrar los ojos a lo más fecundo y característico de la realidad histórica y cultural, hablar del mestizaje americano como de un fenómeno racial limitado a ciertos países, clases sociales o épocas". "Lo verdaderamente importante y significativo fue el encuentro de hombres de distintas culturas en el sorprendente escenario de la América. Ése y no otro es el hecho definidor del Nuevo Mundo". USLAR-PIETRI, Arturo. "El Mestizaje y el Nuevo Mundo". In: En busca del Nuevo Mundo. 1 ed. México: Fondo de Cultura Económica, 1969. (pp 13, 14).

2 - MARTÍ, José. "Nuestra América". In: Letras Fieras. La Habana: Letras Cubanas, 1985. (p 29)

3 - USLAR-PIETRI, Arturo. op. cit. (p 10) 
4 - LeZAMA LIMA, José. "Imagem de América Latina". In: América Latina en su cultura. 4 ed. México: Siglo Veintiuno, 1977. (pp 464, 465)

5 - IDEM. (p 468)

6 - "No, nosotros no hemos vivido nuestra história; la hemos padecido como una catástrofe o como un castigo. (...) No hemos sido sujetos de la história". PAZ, Octavio. "Poesía Latinoamericana". In: El Signo y el Gabarato. 2 ed. México: J. Mortíz, 1975.

7 - IDEM. (p 5)

8 - PAZ, Octavio. "Os Filhos de Malinche". In: O labirinto da Solidão. (p 75)

9 - PAZ, Octavio. "Os Filhos da Malinche". In: O Labirinto da Solidão. (p 82)

10 - USLAR-PIETRI, Arturo. op.cit. (p 15)

11 - FERNÁNDEZ MORENO, César. "Introducción". In: América Latina en su Cultura. 4 ed. México: Siglo

Veintiuno, 1977. (p 7)

\section{BIBLIOGRAFIA}

FERNÁNDEZ MORENO, César. (org) América Latina en su Cultura. 4 ed. México: Siglo Veitiuno, 1977. MARTí, José. Nuestra América. In: Letras Fieras. La Habana: Letras Cubanas, 1985.

PAZ, Octavio. Alrededores de la literatura hispanoamericana. In: Mediaciones. Barcelona: Editorial Seix Barral, 1979.

Os Filhos da Malinche. In: O Labirinto da Solidão.

Poesia Latinoamericana. In: El Signo y el Gabarato. 2 ed. México: Joaquín Mortiz,1975.

USLAR-PIETRI, Arturo. El Mestizaje y el Nuevo Mundo. In: En Busca del Nuevo Mundo. 1 ed. México: Fondo de Cultura Económica, 1969. 